\title{
Protective effect of allicin on high glucose/hypoxia-induced aortic endothelial cells via reduction of oxidative stress
}

\author{
SHU-LI WANG ${ }^{1,2^{*}}$, DE-SHAN LIU ${ }^{1 *}$, ER-SHUN LIANG ${ }^{1,3^{*}}$, YAN-HUA GAO $^{1}$, \\ YING CUI ${ }^{4}$, YU-ZHAO LIU ${ }^{4}$ and WEI GAO ${ }^{1}$ \\ ${ }^{1}$ Department of Traditional Chinese Medicine, Qilu Hospital of Shandong University, Jinan, Shandong 250012; \\ ${ }^{2}$ Department of Geriatrics, Linyi People's Hospital, Linyi, Shandong 276003; \\ ${ }^{3}$ Shandong University School of Medicine; ${ }^{4}$ Key Laboratory of Cardiovascular Remodeling and \\ Function Research, Qilu Hospital of Shandong University, Jinan, Shandong 250012, P.R. China
}

Received February 27, 2015; Accepted August 3, 2015

DOI: $10.3892 /$ etm.2015.2708

\begin{abstract}
This study was designed to explore the protective effect of allicin on aortic endothelial cell injury induced by high glucose/hypoxia and to investigate the corresponding mechanisms. The primary-cultured murine aortic endothelial cells were subcultured. The third passage of cells was adopted and randomly divided into five groups: The normal group (NG), the mannitol group (MG), the high-glucose/hypoxia group (HG), the allicin group (AG) and the protein kinase $\mathrm{C}$ (PKC) inhibitor group (GG). The general morphology was observed under an inverted phase-contrast microscope and cell viability was assessed using the MTT assay. Intracellular reactive oxygen species (ROS) levels in the endothelial cells were quantified using dihydroethidium staining. The levels of 8-hydroxydeoxyguanosine (8-OHdG), nuclear factor- $\kappa \mathrm{B}$ $(\mathrm{NF}-\kappa \mathrm{B}), \mathrm{NADPH}$ oxidase 4 (Nox4) and hypoxia-inducible factor-1 $\alpha$ (HIF-1 $\alpha)$ and the activity of PKC were measured using ELISA. A quantitative polymerase chain reaction (qPCR) was adopted to evaluate the mRNA expression of Nox4, HIF- $1 \alpha$ and NF- $\kappa$ B. The altered cell morphology observed in $\mathrm{HG}$ was notably ameliorated in the $\mathrm{AG}$ and GG. The protein levels of 8-OHdG, NF- $\mathrm{BB}$, Nox4, HIF-1 $\alpha$ and PKC in the HG were higher than those in the other groups. Furthermore, the cell viability in the AG was significantly increased and the protein levels of $8-\mathrm{OHdG}, \mathrm{NF}-\kappa \mathrm{B}$, Nox $4, \mathrm{HIF}-1 \alpha$ and PKC were significantly decreased compared with those in the HG. The ROS production was found to be increased in
\end{abstract}

Correspondence to: Dr De-Shan Liu, Department of Traditional Chinese Medicine, Qilu Hospital of Shandong University, 107 Wenhua Xi Road, Jinan, Shandong 250012, P.R. China

E-mail: liudeshan@sdu.edu.cn

"Contributed equally

Key words: oxidative stress, allicin, NADPH oxidase 4, hypoxiainducible factor-1 $\alpha, 8$-hydroxydeoxyguanosine the HG cells, while there was a significant decrease in the AG cells. These data indicate that allicin exerts a protective effect against high glucose/hypoxia-induced injury in aortic endothelial cells through its antioxidative action, which may involve the inhibition of the PKC pathway and regulation of HIF-1 $\alpha$.

\section{Introduction}

Diabetes mellitus is a serious social health problem, with diabetes-related vascular complications representing a major public health burden. According to statistics, $>40 \%$ of patients hospitalized with acute myocardial infarction have clinical diabetes, and another $35 \%$ exhibit impaired glucose tolerance (1). Excessive production of reactive oxygen species (ROS) and the subsequent increase in oxidative stress under high-glucose conditions play a critical role in this pathology (2). The overproduction of ROS, including superoxide anion radicals, hydrogen peroxide and hydroxyl radicals, can prominently damage nucleic acids, lipids and proteins and result in cellular necrosis, tissue structural damage and functional disorder (3). In the setting of hypoxia, hypoxia-inducible factor- $1 \alpha$ (HIF-1 $\alpha$ ) increases in response to ischemia. HIF-1 $\alpha$ is a key regulator of oxygen homeostasis, which restores blood flow to ischemic regions (4); however, sustained and prolonged activation of the HIF-1 $\alpha$ pathway induces cell death due to the subsequent activation of p53 and other associated genes (5).

Among the currently available medications for diabetes, natural products have drawn increasing attention. As a traditional Chinese herbal medicine, garlic has been used to treat a range of diseases for thousands of years. Allicin is one of the main active components in garlic and exerts several therapeutic effects, such as promoting insulin sensitivity $(6,7)$, decreasing blood glucose levels $(8,9)$, regulating lipid metabolism $(10,11)$, reducing homocysteine levels (12), attenuating superoxide production (13) and limiting inflammation and fibrogenesis. Given the role of oxidative stress within the etiology and pathogenesis of diabetic complications, the present study utilized an in vitro model of diabetes-associated oxidative stress using aortic endothelial cells cultured under high-glucose/hypoxic 
conditions to clarify the possible mechanism of allicin on diabetic macrovascular complications.

\section{Materials and methods}

Materials. The experiment was carried out in the Institute of Basic Medical Sciences, Qilu Hospital of Shandong University (Jinan, China) between February and September, 2014. The murine aortic endothelial cells were obtained from CHI Scientific, Inc. (Jiangyin, China). Xanthine (X), xanthine oxidase (XO), MTT, trypsin, and GF109203x [an inhibitor of protein kinase $\mathrm{C}$ (PKC)] were purchased from Sigma-Aldrich (St. Louis, MO, USA). Allicin was provided by Xuzhou Laien Pharmaceutical Co. Ltd. (Xuzhou, China). Endothelial cell medium (ECM) was provided by Sciencell Research Laboratories (Carlsbad, CA, USA) and TRIzol ${ }^{\circledR}$ was obtained from Gibco-BRL (Grand Island, NY, USA). Culture flasks and 6-, 12-, 24- and 96-well culture plates were purchased from Sigma-Aldrich. 8-Hydroxydeoxyguanosine (8-OHdG), nuclear factor- $\kappa \mathrm{B}(\mathrm{NF}-\kappa \mathrm{B}), \mathrm{NADPH}$ oxidase 4 (Nox4), HIF-1 $\alpha$ and PKC test kits were obtained from Nanjing Jiancheng Bioengineering Institute (Nanjing, China). Taq DNA polymerase and oligo (dt) were provided by Fermentas (Thermo Fisher Scientific, Pittsburgh, PA, USA). The primers were synthesized by Sangon Biotech, Co., Ltd. (Shanghai, China), and all other reagents were analytically pure.

Cell cultures. Murine aortic endothelial cells of the third passage were used in this study. Cells were grown in ECM at $37^{\circ} \mathrm{C}$ with $5 \% \mathrm{CO}_{2}$ and $95 \%$ air. The medium was changed every 2 days, and the cells were checked every day using an inverted phase-contrast microscope (CKX41; Olympus Corp., Tokyo, Japan). When the cells had predominantly mixed together and reached $\sim 80 \%$ confluence, the medium was abandoned and the cells were gently washed twice with phosphate-buffered saline (PBS), prior to detachment from the culture flask, with the aid of $0.2 \%(\mathrm{w} / \mathrm{v})$ trypsin for 2-3 min. A single cell suspension was generated, and the cells were plated in 6-, 12-, 24- or 96-well plates.

Grouping and treatments. Allicin injection, $\mathrm{X} / \mathrm{XO}$ and GF109203x were prepared in serum-free medium at $10 \mu \mathrm{g} / \mathrm{ml}, 1 \mathrm{mmol} / 1 / 20 \mathrm{U} / 1$ and $10 \mu \mathrm{mol} / 1$, respectively. The murine aortic endothelial cells in the exponential growth phase were randomly divided into five groups: The normal group (NG), the mannitol group (MG), the high-glucose/hypoxia group (HG), the allicin group (AG) and the PKC inhibitor (GF109203x) group (GG). The cells of the NG and MG were respectively incubated with serum-free ECM and mannitol $(25 \mathrm{mmol} / \mathrm{l})$ for $24 \mathrm{~h}$. The cells of the HG, AG and GG were respectively incubated with $\mathrm{X} / \mathrm{XO}(1 \mathrm{mmol} / 1 / 20 \mathrm{U} / \mathrm{l})$, allicin $(10 \mu \mathrm{g} / \mathrm{ml})$ plus $\mathrm{X} / \mathrm{XO}(1 \mathrm{mmol} / \mathrm{l} / 20 \mathrm{U} / \mathrm{l})$, and GF109203x (10 $\mu \mathrm{mol} / \mathrm{l})$ plus $\mathrm{X} / \mathrm{XO}(1 \mathrm{mmol} / \mathrm{l} / 20 \mathrm{U} / \mathrm{l})$ for $40 \mathrm{~min}$, prior to the supernatant solution being abandoned and the cells being treated with glucose $(25 \mathrm{mmol} / \mathrm{l})$, allicin $(10 \mu \mathrm{g} / \mathrm{ml})$ plus glucose (25 mmol/l), and GF109203x (10 $\mu \mathrm{mol} / \mathrm{l})$ plus glucose $(25 \mathrm{mmol} / \mathrm{l})$, respectively, for $24 \mathrm{~h}$. Following each of the above treatment regimens, the supernatant and culture cells were collected. The collected cells were resuspended in PBS. In order to measure the components within cells, the freeze-thawing method was adopted to break up the cells.

Cell viability assay. Following the different treatments, the morphological changes were observed under a phase-contrast microscope (Olympus Corp.). In addition, MTT assays were performed to assess the cell viability. First, cell viability was assessed using MTT when the cells were cultured in different allicin concentrations of 50,20,10,5 and $2.5 \mu \mathrm{g} / \mathrm{ml}$ (all diluted in serum-free ECM). In brief, the cells of the six groups (the normal control group and the five groups of different allicin concentrations) were seeded into 96 -well plates at a density of $1 \times 10^{4}$ cells per well. Upon reaching $\sim 80 \%$ confluence, the cells were incubated with different concentrations of allicin for $24 \mathrm{~h}$. The supernatant was then abandoned, and $200 \mu \mathrm{l}$ serum-free medium, as well as $20 \mu \mathrm{l}$ MTT dye solution $(5 \mathrm{mg} / \mathrm{ml})$, was added to each well. Following the incubation of the samples at $37^{\circ} \mathrm{C}$ for $4 \mathrm{~h}$, the MTT/medium solution was removed and $150 \mu \mathrm{l}$ dimethylsulfoxide was added to dissolve the formazan product in each well on a concentrating table for $15 \mathrm{~min}$. The optical density of each well was measured using an ELISA microplate reader (Bio-Rad Laboratories, Inc., Hercules, CA, USA) at a wavelength of $290 \mathrm{~nm}$. In addition, the cell viability in the NG, MG, HG, AG and GG was assessed using MTT following treatment with the different interventions for $24 \mathrm{~h}$.

Dihydroethidium (DHE) staining to measure ROS. DHE, which is used as a relatively specific measurement for the superoxide anion, is an oxidative fluorescent dye that undergoes a two-electron oxidation to form the DNA-binding fluorophore ethidium bromide. The DHE (Vigorous Biotechnology Beijing Co., Ltd., Beijing, China) staining for superoxide was carried out as previously described (14). Briefly, the cells were treated with the aforementioned interventions for $24 \mathrm{~h}$. Following the removal of the supernatant solution, the cells were cultured in DHE $(10 \mu \mathrm{mol} / \mathrm{l})$ diluted with PBS in a light-protected, humidified chamber at $37^{\circ} \mathrm{C}$ for $30 \mathrm{~min}$. Once the cells had been washed twice with PBS to remove the uncombined fluorescence probe, fluorescent images were obtained using a fluorescence microscope. The mean fluorescence intensity was measured using Image-Pro Plus 6.0 software (Media Cybernetics, Inc., Rockville, MD, USA) for quantification. The generation of superoxide was demonstrated by red fluorescent labeling. Non-stained cells were used as a background control. The average of three DHE-stained images was taken as the value for each group.

ELISA. The levels of 8-OHdG, NF- $\kappa \mathrm{B}, \mathrm{Nox} 4, \mathrm{HIF}-1 \alpha$ and PKC in the cells were determined by ELISA, according to instructions of each assay kit. Aortic endothelial cells were treated as previously described for $24 \mathrm{~h}$. Following the removal of the supernatant solution, the cells were washed twice with ice-cold PBS, scraped from the plate with trypsin and centrifuged at $1,301 \mathrm{rpm}$ for $5 \mathrm{~min}$ at $4^{\circ} \mathrm{C}$. The cells were resuspended in PBS. The freeze-thawing method was performed to break up the cells.

Reverse transcription-quantitative polymerase chain reaction $(R T-q P C R)$. RT-qPCR was performed in accordance 


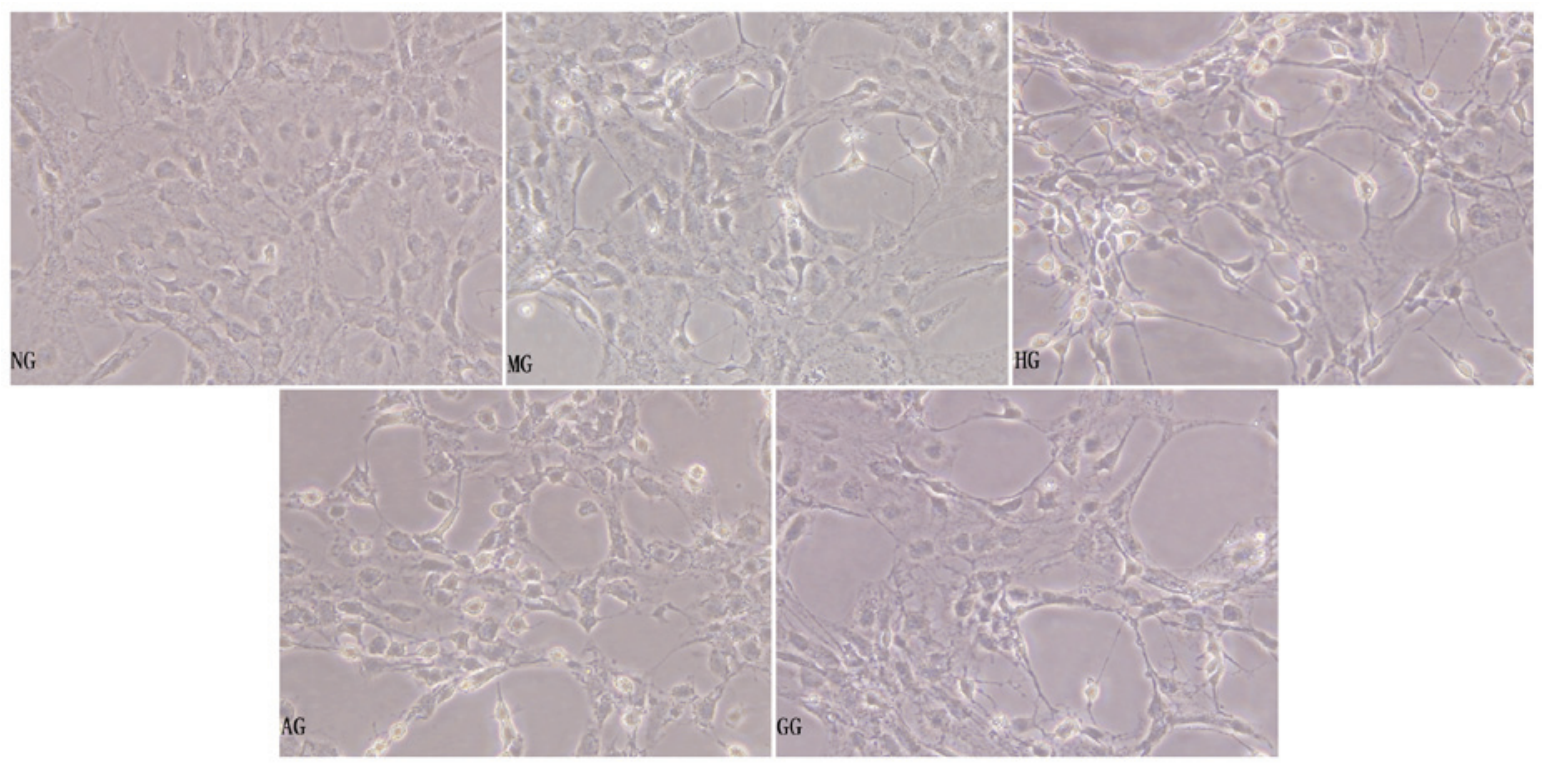

Figure 1. General morphological observation of aortic endothelial cells under the inverted phase-contrast microscope. Images are representative of each group (magnification, x200). NG, normal group; MG, mannitol group; HG, high glucose/hypoxia group; AG, allicin group; GG, PKC inhibitor (GF109203x) group.

with the method described in our previous study (15). Briefly, total RNA was extracted using TRIzol reagent, following the manufacturer's instructions (Gibco-BRL). cDNA was synthesized using a commercial reverse transcription kit (Fermentas; Thermo Fisher Scientific, Waltham, MA, USA). The sequences of the primers and cycle conditions were as follows: i) HIF-1 $\alpha$ sense, 5'-TCAAGTCAGCAACGTGGA AG-3' and antisense, 5'-TATCGAGGCTGTGTCGACTG-3' (amplification product, $198 \mathrm{bp} ; 94^{\circ} \mathrm{C}$ for $30 \mathrm{sec}, 59^{\circ} \mathrm{C}$ for $30 \mathrm{sec}$ and $72^{\circ} \mathrm{C}$ for $1 \mathrm{~min}$, for 35 cycles); ii) Nox 4 sense, 5'-TAGCTGCCCACTTGGTGAACG-3' and antisense, 5'-TGTAACCATGAGGAACAATACCACC-3' (amplification product, $170 \mathrm{bp} ; 94^{\circ} \mathrm{C}$ for $30 \mathrm{sec}, 59^{\circ} \mathrm{C}$ for $30 \mathrm{sec}$ and $72^{\circ} \mathrm{C}$ for $1 \mathrm{~min}$, for 30 cycles); iii) NF- $\mathrm{NB}$ sense, 5'-GTATTG CTGTGCCTACCCGAAAC-3' and antisense, 5'-GTTTGA GATCTGCCCTGATGGTAA-3' (amplification product, $134 \mathrm{bp} ; 94^{\circ} \mathrm{C}$ for $30 \mathrm{sec}, 55^{\circ} \mathrm{C}$ for $30 \mathrm{sec}$ and $72^{\circ} \mathrm{C}$ for $1 \mathrm{~min}$, for 30 cycles); iv) $\beta$-actin sense, $5^{\prime}$-TGGCACCCAGCACAA TGAA-3' and antisense, 5'-CTAAGTCATAGTCCGCCT AGAAGCA-3' (amplification product, $188 \mathrm{bp} ; 94^{\circ} \mathrm{C}$ for $30 \mathrm{sec}, 59^{\circ} \mathrm{C}$ for $30 \mathrm{sec}$ and $72^{\circ} \mathrm{C}$ for $1 \mathrm{~min}$, for 30 cycles). The mean value of the replicates for each sample was calculated and expressed as the cycle threshold $(\mathrm{Ct})$. The gene expression was then calculated as the difference $(\Delta \mathrm{Ct})$ between the $\mathrm{Ct}$ value of the target gene and the $\mathrm{Ct}$ value of $\beta$-actin.

Statistical analysis. Data are presented as the mean \pm standard deviation. Analysis of variance was used to compare the mean values of more than two groups. Differences were considered significant at $\mathrm{P}<0.05$. All statistical calculations were performed using SPSS 13.0 software (SPSS, Inc., Chicago, IL, USA).

\section{Results}

General morphological observation under the inverted phase-contrast microscope. Under high-glucose/hypoxic

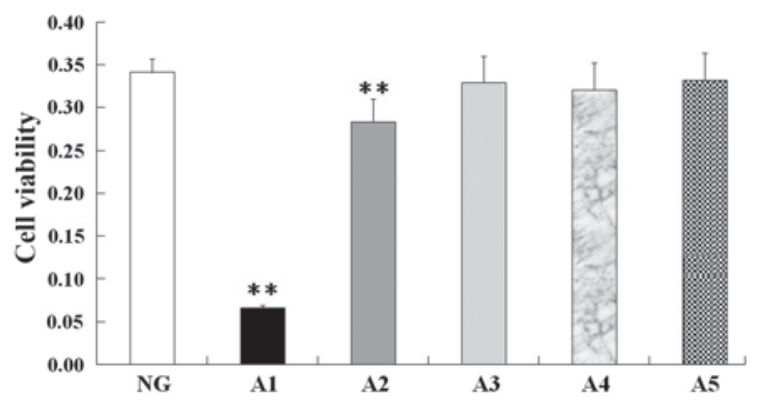

Figure 2. Effect of different concentrations of allicin on aortic endothelial cell viability. Data are expressed as the mean \pm standard deviation $(n=10$ per group). ${ }^{* *} \mathrm{P}<0.01$ vs. NG. NG, normal group; A1, allicin at $50 \mu \mathrm{g} / \mathrm{ml}$; A2, allicin at $20 \mu \mathrm{g} / \mathrm{ml} ; \mathrm{A} 3$, allicin at $10 \mu \mathrm{g} / \mathrm{ml}$; A4, allicin at $5 \mu \mathrm{g} / \mathrm{ml} ; \mathrm{A} 5$, allicin at $2.5 \mu \mathrm{g} / \mathrm{ml}$.

conditions for $24 \mathrm{~h}$, the aortic endothelial cells became shrunken, the intercellular connection was lessened, some of the cells became exfoliated and a few of the cells were found to be floating in the supernate (Fig. 1, HG). The morphology of the MG cells was not obviously changed compared with that of the NG cells (Fig. 1, MG). Compared with the HG cells, the cells in the AG had more complete cell bodies with visible processes, indicating that allicin played a protective role in the injured cells (Fig. 1, AG).

Viability of aortic endothelial cells. MTT assay revealed no significant differences in cell viability between the normal control group and the 10,5 and $2.5 \mu \mathrm{g} / \mathrm{ml}$ allicin groups (Fig. 2, A3, A4 and A5); however, the cell viability of the 50 and $20 \mu \mathrm{g} / \mathrm{ml}$ allicin groups was significantly decreased compared with that of the normal control group $(\mathrm{P}<0.01)$ (Fig. 2, A1 and A2). Based on these findings, $10 \mu \mathrm{g} / \mathrm{ml}$ allicin was selected as the final treatment concentration. In addition, as shown in Fig. 3, an evident decrease in viability was observed in the cells under high-glucose/hypoxic conditions compared with the cells of the NG $(\mathrm{P}<0.01)$; however, in experimental 


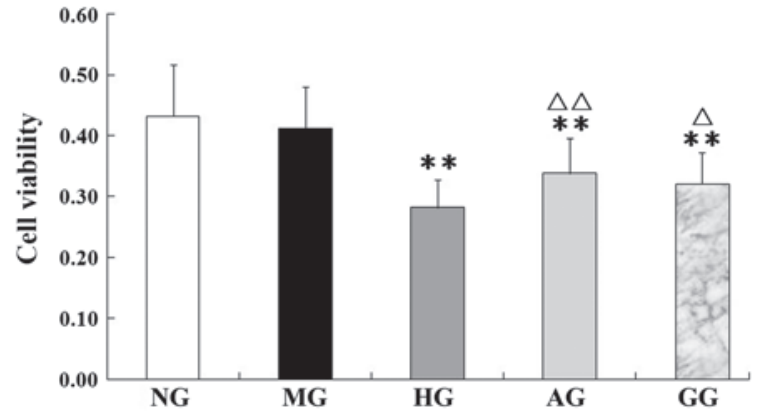

Figure 3. Cell viability of aortic endothelium treated with different interventions. Data are expressed as the mean \pm standard deviation ( $\mathrm{n}=14$ per group). ${ }^{* *} \mathrm{P}<0.01$ vs. $\mathrm{NG} ;{ }^{\wedge} \mathrm{P}<0.05$ and ${ }^{\Delta \Delta} \mathrm{P}<0.01$ vs. HG. NG, normal group; $\mathrm{MG}$, mannitol group; HG, high glucose/hypoxia group; AG, allicin group; GG, PKC inhibitor (GF109203x) group.
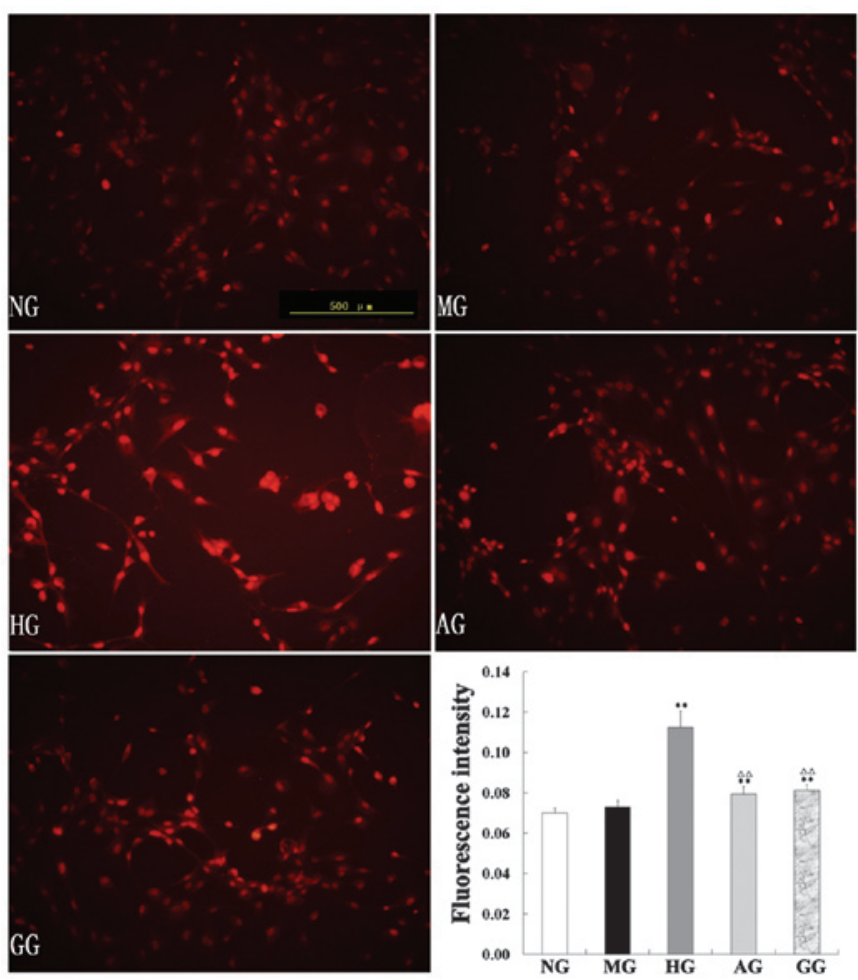

Figure 4. Reactive oxygen species levels of aortic endothelial cells assessed by dihydroethidium staining under a fluorescence microscope. Image-Pro Plus 6.0 image analysis software was used to analyze the results. Images are representative of each group. ${ }^{* *} \mathrm{P}<0.01$ vs. NG; ${ }^{\Delta} \mathrm{P}<0.05$ and ${ }^{\Delta \Delta} \mathrm{P}<0.01$ vs. HG. $\mathrm{NG}$, normal group; MG, mannitol group; HG, high glucose/hypoxia group; AG, allicin group; GG, PKC inhibitor (GF109203x) group.

conditions with allicin or GF109203x the cell viability was significantly increased compared with that of the HG $(\mathrm{P}<0.01$ or $\mathrm{P}<0.05)$. Allicin and GF109203x exhibited similar effects on cell viability.

Effect on ROS. ROS production in the endothelial cells of the five groups was assessed by DHE staining. DHE is a fluorescent dye that specifically reacts with intracellular ROS and is converted to the red fluorescent compound ethidium, which then binds irreversibly to double-stranded DNA and appears as nuclear staining. As shown in Fig. 4, the intensity of DHE fluorescence in the endothelial cells in the HG was

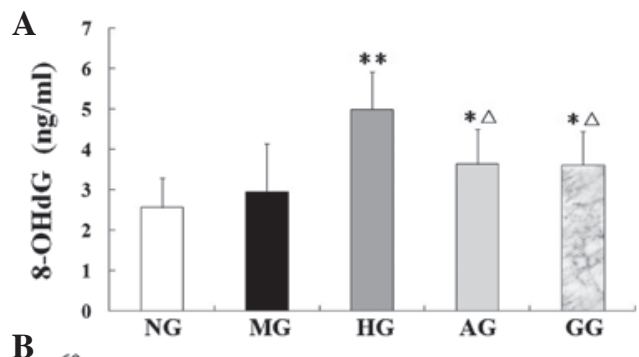

B
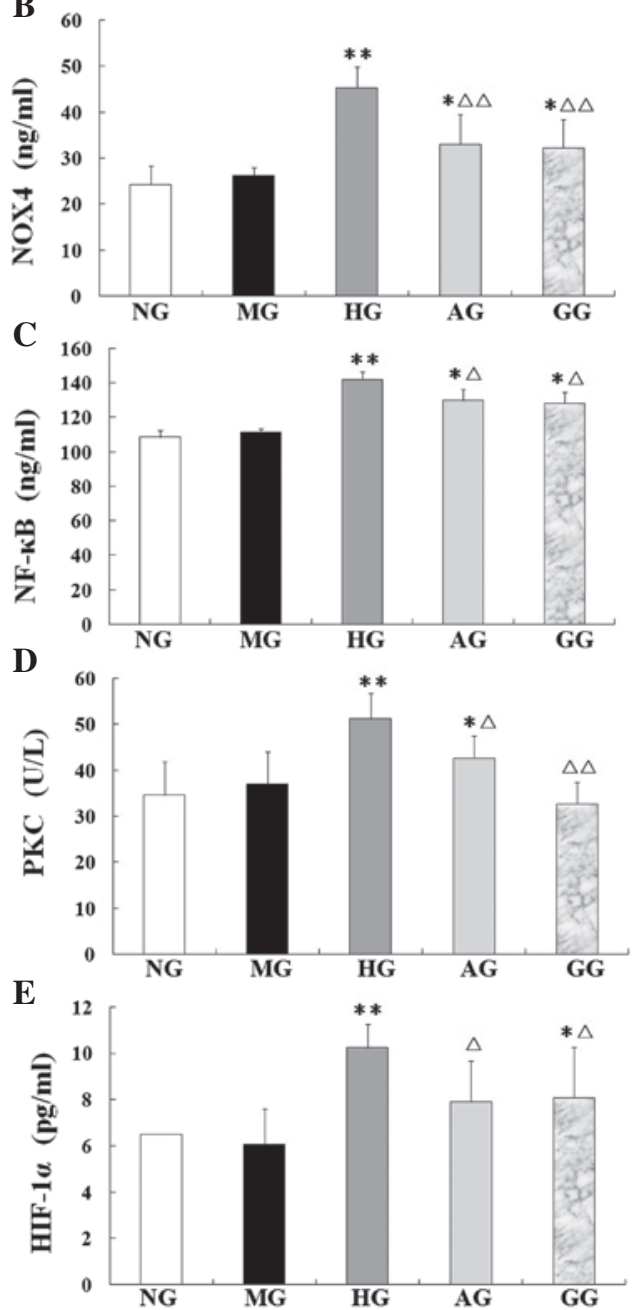

Figure 5. Levels of (A) 8-OHdG, (B) Nox4, (C) NF-кB, (D) PKC and (E) HIF-1 $\alpha$ in aortic endothelial cells treated with different interventions. Data are presented as the mean \pm standard deviation ( $\mathrm{n}=10$ per group). ${ }^{*} \mathrm{P}<0.05$ and ${ }^{* *} \mathrm{P}<0.01$ vs. NG; ${ }^{\Delta} \mathrm{P}<0.05$ and ${ }^{\Delta \Delta} \mathrm{P}<0.01$ vs. HG. NG, normal group; MG, mannitol group; HG, high glucose/hypoxia group; AG, allicin group; GG, PKC inhibitor (GF109203x) group; 8-OHdG, 8-hydroxydeoxyguanosine; Nox4, NADPH oxidase 4 ; NF- $\kappa B$, nuclear factor- $\kappa \mathrm{B}$; PKC, protein kinase $\mathrm{C}$; HIF-1 $\alpha$, hypoxia-inducible factor- $1 \alpha$.

significantly enhanced compared with that in the NG; allicin significantly downregulated the levels of $\operatorname{ROS}(\mathrm{P}<0.01)$.

Protein levels of 8-OHdG, NF- $\kappa$ B, Nox4 and HIF-1 $\alpha$ and activity of $P K C$. In the $\mathrm{HG}$, the protein levels of $8-\mathrm{OHdG}$, NF- $\kappa$ B, Nox 4 and HIF-1 $\alpha$ and the activity of PKC were significantly increased compared with those of the NG (all $\mathrm{P}<0.01$ ). In the AG, however, the five parameters were notably restored, showing a significant decrease compared with the levels in the HG $(\mathrm{P}<0.05$ or $\mathrm{P}<0.01)$ (Fig. 5). 

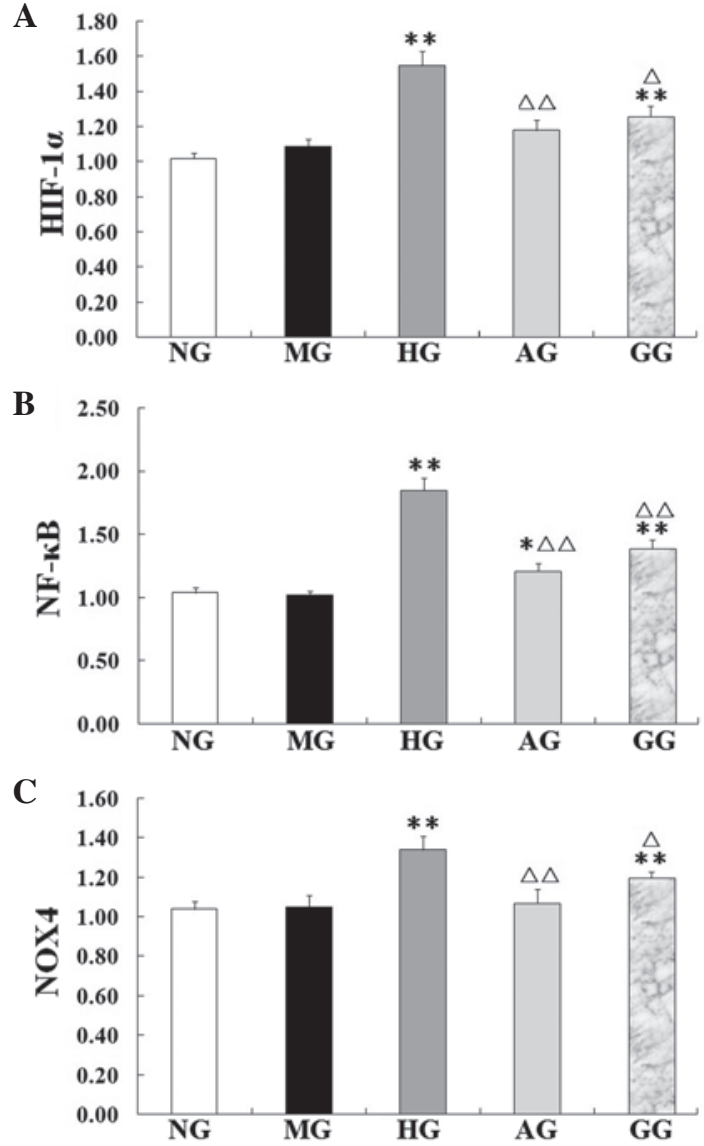

Figure 6. mRNA expression of (A) HIF-1 $\alpha$, (B) NF- $\kappa$ B and (C) Nox4 in aortic endothelial cells examined by a reverse transcription-quantitative polymerase chain reaction. Data are presented as the mean \pm standard devia-

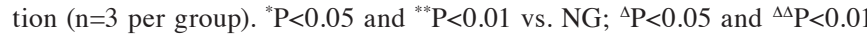
vs. HG. NG, normal group; MG, mannitol group; HG, high glucose/hypoxia group; AG, allicin group; GG, PKC inhibitor (GF109203x) group; HIF-1 $\alpha$ hypoxia-inducible factor- $1 \alpha$; Nox4, NADPH oxidase 4 ; NF- $\kappa B$, nuclear factor- $\mathrm{\kappa} \mathrm{B}$.

$m R N A$ expression of $N F-\kappa B, N o x 4$ and HIF-1 $\alpha$. In the HG, the NF- $\kappa B$, Nox 4 and HIF-1 $\alpha$ mRNA expression was found to be significantly increased compared with the expression in the $\mathrm{NG}(\mathrm{P}<0.01)$, which suggested that high glucose/hypoxia could induce the expression of these mRNAs (Fig. 6). Compared with the HG, however, the mRNA expression of NF- $\kappa B$, Nox4 and HIF- $1 \alpha$ in the AG was significantly decreased $(\mathrm{P}<0.05$ or $\mathrm{P}<0.01)$.

\section{Discussion}

In diabetes mellitus, the risk of atherosclerosis is enhanced, which results in an increase in the incidence of both cardiovascular and cerebrovascular diseases, such as myocardial infarction and cerebral ischemic attacks. Cardiovascular disease is the major cause of morbidity and mortality in diabetic patients (16). The exact mechanisms responsible for this accelerated development of atherosclerosis in diabetes have remained elusive, but oxidative stress appears to play a major role. Several studies have reported that the overproduction of ROS by the mitochondrial electron transport chain is responsible for hyperglycemia-induced oxidative damage and the pathogenesis of diabetic complications (17-21).
Hyperglycemia promotes glucose oxidation and protein glycation, impairs DNA repair, with resultant DNA cleavage, and generates ROS, thereby leading to increased oxidative stress (22). Oxidative stress is considered to be the final common pathway through which the hyperglycemia-related pathways (PKC and polyol) can trigger the chronic complications of diabetes. Cumulative oxidant-mediated damage and cellular dysfunction are a result of an imbalance between ROS generation and antioxidant capacity. Furthermore, studies have found that there is a hypoxic microenvironment in diabetes, which is closely associated with the oxidative stress induced by hyperglycemia and plays an important role in diabetic complications (Amandine,Chavez). The development of therapeutic strategies aimed at the removal of free radicals or the prevention of their formation is therefore necessary.

To determine the injury elicited in aortic endothelial cells by high glucose/hypoxia and investigate whether allicin would effectively ameliorate the damage, the expression of oxidative stress-related markers was examined in endothelial cells cultured in high glucose $(25 \mathrm{mmol} / \mathrm{l}$ for $24 \mathrm{~h})$ and hypoxia [X/XO (1 mmol/1/20 U/l) for $40 \mathrm{~min}]$, simulating a diabetic microenvironment in vivo. The possible associated mechanisms were also explored. Since GF109203x is a highly specific PKC inhibitor, it was selected for use as a control. The study showed that the cells in the HG became shrunken and intercellular connections were lessened; furthermore, some of the cells became exfoliated and a few of the cells were observed to be floating. The MG was established to counteract the possible cellular injury by hyperosmosis, and it was found that the cell morphology of the MG was not obviously changed compared with that of the NG. Compared with the HG, the cells in the AG had more complete cell bodies with visible processes, which indicated that allicin played a protective role in the injured cells. Consistent with the MTT results, it was observed that allicin significantly inhibited cell death. Furthermore, a relatively abundant generation of ROS was measured in the cells of the HG by the DHE fluorescence probe. As shown in Fig. 4, allicin significantly downregulated the levels of ROS, showing its effective attenuation of the oxidative stress. The increase in ROS production observed in the endothelial cells of the HG was associated with an increase in the generation of Nox4 and 8-OHdG. NADPH oxidases of the Nox family are major sources of ROS, and the level of 8-OHdG is considered to be a marker of oxidative DNA damage (23). Our preliminary results confirmed the enhancement of oxidative damage to DNA in the HG; however, the damage was markedly attenuated when the cells were treated with allicin. These data suggested that allicin had significantly protective antioxidative effects against high glucose/hypoxia-induced injury in aortic endothelial cells.

To the best of our knowledge, the persistent upregulation of PKC is recognized as an initial event leading to insulin resistance, cardiac disease and nephropathy in diabetes. Numerous studies (24-26) have previously reported that multiple PKC isoforms are activated in the vascular tissue of diabetic animal models, and the overactivation of the PKC pathway is a key mediator of diabetic vascular complications. The understanding of how hyperglycemia-induced oxidative stress ultimately leads to tissue damage has been advanced considerably (27), and strategies to reduce oxidative stress may 
exert favorable effects on the progression of diabetes; however, effective therapy to prevent or delay the development of this damage remains limited (28). The present results revealed that the level of PKC protein significantly increased in the murine aortic endothelial cells under high-glucose/hypoxia conditions, and the increase was mitigated by allicin, which demonstrated that the protective effects of allicin against the injury induced by high glucose/hypoxia involved the inhibition of the PKC pathway. PKC has been noted to contribute to the activation of NADPH oxidases in multiple cells (29). The Nox system is considered to be a key contributor to the generation of ROS in numerous cell types and tissues (30). Increased generation of ROS and impaired antioxidant defenses contribute to oxidative stress in diabetes (21). Previous studies have shown increased levels of NADPH oxidase subunits in the vasculature and kidney tissue of diabetic rodents $(31,32)$. Nox4 was initially identified as a kidney NADPH oxidase, but it has since been shown that Nox4 is also abundant in vascular cells (33). There is additionally evidence that Nox 4 contributes to oxidative stress in cardiovascular diseases $(34,35)$. The present study showed a significant increase in Nox4 levels in the HG compared with those in the NG. Allicin significantly reduced the Nox4 mRNA and protein expression. These results suggest that high glucose/hypoxia increased the Nox4 levels, which caused an imbalance between the production of free radicals and the antioxidant defense system. Collectively, these data indicate that high-glucose conditions induce increased oxidative stress by activating the PKC pathway, which in turn mediates the increase in NADPH oxidase activity and Nox4 upregulation. Allicin can inhibit the PKC pathway, decrease Nox4-derived ROS and the endothelial cell injury induced by oxidative stress. The effects of allicin in the present study were similar to those of the PKC inhibitor GF109203x.

$\mathrm{NF}-\kappa \mathrm{B}$ is a pleiotropic, oxidant-sensitive transcription factor that is required for the transcription of the majority of proinflammatory molecules, including adhesion molecules, enzymes, cytokines and chemokines, which mediate the recruitment and retention of monocytes in the subendothelial space; a key early step in the atherosclerotic process. It has also been indicated that the activation of PKC is involved in the hyperglycemia-induced sustained activation of the transcription factor $\mathrm{NF}-\kappa \mathrm{B}$ (36). In the present study, as shown in Figs. 4 and 5, a significant increase was triggered by high glucose/hypoxia not only in the NF- $\kappa \mathrm{B}$ mRNA level, but also in the NF- $\kappa \mathrm{B}$ protein expression. Based on these findings, it is indicated that high-glucose conditions induced the activation of the transcription factor $\mathrm{NF}-\kappa \mathrm{B}$ through the upregulation of PKC. The upregulation of the PKC pathway leads to the concurrent upregulation of NADPH oxidase and increase in ROS production, which can damage endothelial cells and induce the expression of $\mathrm{NF}-\kappa \mathrm{B}$, mediating the recruitment and retention of numerous inflammatory factors that further aggravate oxidative stress. Allicin can downregulate both the PKC activation and $N F-\kappa B$ expression. The inhibition of the PKC pathway should be considered as a target for the treatment of diabetes and its associated complications, and the present study showed that allicin inhibited the PKC pathway with a similar efficacy to that of the PKC inhibitor GF109203x.

Hypoxia has a prominent effect on all diabetic complications (37). HIF-1 $\alpha$ is highly labile under normal oxygen conditions; however, under hypoxia it is strongly stabilized by ROS, preventing its hydroxylation and proteasomal degradation $(38,39)$. In the present study, X/XO was used to establish the oxygen radical production system, simulating hypoxic conditions. HIF-1-dependent gene regulation leads to an adaptation to the hypoxic state, allowing the cell to survive. Anoxia, however, can induce the overexpression of HIF-1 $\alpha$, which leads to apoptosis-related gene expression, resulting in cell injury. In the present study, it was found that, dependent on the extent of the high glucose and hypoxia, HIF-1 $\alpha$ levels also significantly increased. These results showed that endothelial cells incubated under high-glucose/hypoxic conditions expressed significantly high levels of HIF-1 $\alpha$, which were a risk factor for vascular lesion. In addition, allicin downregulated the expression of HIF-1 $\alpha$.

A broad range of antioxidant properties have been attributed to allicin, including direct scavenging of free radicals, maintenance of glutathione and the endogenous antioxidant redox balance, as well as the enhanced expression of the antioxidant enzymes glutathione peroxidase, glutathione reductase, SOD and CAT (13). Furthermore, allicin can suppress the production of certain inflammatory cytokines that have been implicated in the pathogenesis of diabetic complications, including tumor necrosis factor- $\alpha$ and transforming growth factor-1 (40). Specifically, a decrease in oxidative stress has been associated with reduced diabetes-associated atherosclerotic plaque development. As oxidative stress is associated with diabetic complications, antioxidation may be a key factor in the treatment of these diseases. The results of the present study indicate that allicin exerted beneficial effects on the treatment of macroangiopathy and could inhibit endothelial cell apoptosis and promote cellular survival under high-glucose/hypoxic conditions. These data offer a plausible explanation for the effects of allicin in vivo, which appear to be mediated at least partially by the inhibition of the PKC pathway and the consequent decrease in ROS production. In conclusion, the results of the present study suggest that allicin exerts protective effects via the inhibition of the high-glucose/hypoxia-induced upregulation of the PKC pathway and the subsequent activation of NADPH oxidase, increased ROS production, endothelial cell injury, 8-OHdG release and $\mathrm{NF}-\kappa \mathrm{B}$ upregulation. Inhibition of the PKC pathway may be the common protective mechanism of allicin in diabetes.

\section{Acknowledgements}

The authors would like to thank Dr Chuanju Liu and Mr. Brendon Richbourgh at the New York University School of Medicine for checking the manuscript.

\section{References}

1. Norhammar A, Tenerz A, Nilsson G, Hamsten A, Efendíc S, Rydén L and Malmberg K: Glucose metabolism in patients with acute myocardial infarction and no previous diagnosis of diabetes mellitus: A prospective study. Lancet 359: 2140-2144, 2002.

2. Rolo AP and Palmeira CM: Diabetes and mitochondrial function: Role of hyperglycemia and oxidative stress. Toxicol Appl Pharmcol 212: 167-178, 2006.

3. Olmez I and Ozyurt H: Reactive oxygen species and ischemic cerebrovascular disease. Neurochem Int 60: 208-212, 2012. 
4. Laderoute KR: The interaction between HIF-1 and AP-1 transcription factors in response to low oxygen. Semin Cell Dev Biol 16: 502-513, 2005.

5. Nitatori T, Sato N, Waguri S, Waguri S, Karasawa Y, Araki H, Shibanai K, Kominami E and Uchiyama Y: Delayed neuronal death in the CA1 pyramidal cell layer of the gerbil hippocampus following transcient ischemia is apoptosis. J Neurosci 15: 1001-1011, 1995.

6. Patumraj S, Tewit S, Amatyakul S, Jariyapongskul A, Maneesri S, Kasantikul V and Shepro D: Comparative effects of garlic and aspirin on diabetic cardiovascular complications. Drug Deliv 7: 91-96, 2000

7. Eidi A, Eidi M and Esmaeili E: Antidiabetic effect of garlic (Allium sativum L.) in normal and streptozotocin-induced diabetic rats. Phytomedicine 13: 624-629, 2006.

8. Ashraf R, Khan RA and Ashraf I: Garlic (Allium sativum) supplementation with standard antidiabetic agent provides better diabetic control in type 2 diabetes patients. Pak J Pharm Sci 24: 565-570, 2011.

9. Nasim SA, Dhir B, Kapoor R, Fatima S, Mahmooduzzafar and Mujib A: Alliin obtained from leaf extract of garlic grown under in situ conditions possess higher therapeutic potency as analyzed in alloxan-induced diabetic rats. Pharm Biol 49: 416-421, 2011.

10. Borek C: Garlic reduces dementia and heart-disease risk. J Nutr 136 (3 Suppl): S810-S812, 2006.

11. Ou CC, Tsao SM, Lin MC and Yin MC: Protective action on human LDL against oxidation and glycation by four organosulfur compounds derived from garlic. Lipids 38: 219-224, 2003.

12. Liu DS, Gao W, Liang ES, Wang SL, Lin WW, Zhang WD, Jia Q, Guo RC and Zhang JD: Effects of allicin on hyperhomocysteinemia-induced experimental vascular endothelial dysfunction. Eur J Pharmacol 714: 163-169, 2013.

13. Rajani Kanth V, Uma Maheswara Reddy P and Raju TN: Attenuation of streptozotocin-induced oxidative stress in hepatic and intestinal tissues of Wistar rat by methanolic-garlic extract. Acta Diabetol 45: 243-251, 2008.

14. Guzik TJ, Mussa S, Gastaldi D, Sadowski J, Ratnatunga C, Pillai R and Channon KM: Mechanisms of increased vascular superoxide production in human diabetes mellitus: Role of $\mathrm{NAD}(\mathrm{P}) \mathrm{H}$ oxidase and endothelial nitric oxide synthase. Circulation 105: 1656-1662, 2002.

15. Liu DS, Zhou YH, Liang ES, Li W, Lin WW, Chen FF and Gao W: Neuroprotective effects of the Chinese Yi-Qi-Bu-Shen recipe extract on injury of rat hippocampal neurons induced by hypoxia/reoxygenation. J Ethnopharmacol 145: 168-174, 2013.

16. Bryden KS, Dunger DB, Mayou RA, Peveler RC and Neil HA Poor prognosis of young adults with type 1 diabetes: A longitudinal study. Diabetes Care 26: 1052-1057, 2003.

17. Mäkinen VP, Forsblom C, Thorn LM, Wadén J, Kaski K, Ala-Korpela M and Groop PH: Network of vascular diseases, death and biochemical characteristics in a set of 4,197 patients with type 1 diabetes (the FinnDiane Study). Cardiovasc Diabetol 8: 54, 2009.

18. Brownlee M: The pathobiology of diabetic complications: A unifying mechanism. Diabetes 54: 1615-1625, 2005.

19. Duchen MR: Roles of mitochondria in health and disease. Diabetes 53 (Suppl 1): S96-S102, 2004.

20. Nishikawa T, Edelstein D, Du XL, Yamagishi S, Matsumura T, Kaneda Y, Yorek MA, Beebe D, Oates PJ, Hammes HP, et al: Normalizing mitochondrial superoxide production blocks three pathways of hyperglycaemic damage. Nature 404: 787-790, 2000.

21. Kiritoshi S, Nishikawa T, Sonoda K, Kukidome D, Senokuchi T, Matsuo T, Matsumura T, Tokunaga H, Brownlee M and Araki E: Reactive oxygen species from mitochondria induce cyclooxygenase-2 gene expression in human mesangial cells: Potential role in diabetic nephropathy. Diabetes 52: 2570-2577, 2003.

22. Retinopathy and nephropathy in patients with type 1 diabetes four years after a trial of intensive therapy. The diabetes control and complications trial/epidemiology of diabetes interventions and complications research group. N Engl J Med 342, 381-389, 2000.
23. Tuzgen S, Hamnimoglu H, Tanriverdi T, Kacira T, Sanus G, Atukereny P, Dashti R, Gumustas K, Canbaz B and Kaynar MY: Relationship between DNA damage and total antioxidant capacity in patients with glioblastoma multiforme. Clin Oncol (R Coll Radiol) 19: 177-181, 2007.

24. Inoguchi T, Battan R, Handler E, Sportsman JR, Heath W and King GL: Preferential elevation of protein kinase $\mathrm{C}$ isoform beta II and diacylglycerol levels in the aorta and heart of diabetic rats: Differential reversibility to glycemic control by islet cell transplantation. Proc Natl Acad Sci USA 89: 11059-11063, 1992.

25. Craven PA, Studer RK, Negrete H and DeRubertis FR: Protein kinase $\mathrm{C}$ in diabetic nephropathy. J Diabetes Complications 9: 241-245, 1995.

26. Koya D, Jirousek MR, Lin YW, Ishii H, Kuboki K and King GL: Characterization of protein kinase $\mathrm{C}$ beta isoform activation on the gene expression of transforming growth factor-beta, extracellular matrix components and prostanoids in the glomeruli of diabetic rats. J Clin Invest 100: 115-126, 1997.

27. Brownlee M: Biochemistry and molecular cell biology of diabetic complications. Nature 414: 813-820, 2001.

28. Hamilton CA, Miller WH, Al-benna S, Brosnan J, Drummond RD, McBride MW and Dominiczak AF: Strategies to reduce oxidative stress in cardiovascular diaease. Clin Sci (Lond) 106: 219-234, 2004.

29. Dekker LV, Leitges M, Altschuler G, Mistry N, McDermott A, Roes J and Segal AW: Protein kinase C-beta contributes to NADPH oxidase activation in neutrophils. Biochem J 347: 285-289, 2000.

30. Serrander L, Cartier L, Bedard K, Banfi B, Lardy B, Plastre O, Sienkiewicz A, Fórró L, Schlegel W and Krause KH: NOX4 activity is determined by mRNA levels and reveals a unique pattern of ROS generation. Biochem J 406: 105-114, 2007.

31. Gorin Y, Block K, Hernandez J, Bhandari B, Wagner B, Barnes JL and Abboud HE: Nox4 NAD(P)H oxidase mediates hypertrophy and fibronectin expression in the diabetic kidney. J Biol Chem 280: 39616-39626, 2005.

32. Goyal P, Weissmann N, Rose F, Grimminger F, Schäfers HJ, Seeger $W$ and Hänze J: Identification of novel Nox4 splice variants with impact on ROS levels in A549 cells. Biochem Biophys Res Commun 329: 32-39, 2005.

33. Griendling KK: Novel NAD(P)H oxidases in the cardiovascular system. Heart 90: 491-493, 2004

34. San Martín A, Du P, Dikalova A, Lassègue B, Aleman M, Góngora MC, Brown K, Joseph G, Harrison DG, Taylor WR, et al: Reactive oxygen species-selective regulation of aortic inflammatory gene expression in Type 2 diabetes. Am J Physiol Heart Circ Physiol 292: H2073-H2082, 2007.

35. Thandavarayan RA, Watanabe K, Ma M, Gurusamy N, Veeraveedu PT, Konishi T, Zhang S, Muslin AJ, Kodama M and Aizawa Y: Dominant-negative p38 mitogen-activated protein kinase prevents cardiac apoptosis and remodeling after streptozotocin-induced diabetes mellitus. Am J Physiol Heart Circ Physiol 297: H911-H919, 2009.

36. Yerneni KK, Bai W, Khan BV, Medford RM and Natarajan R: Hyperglycemia-induced activation of nuclear transcription factor kappaB in vascular smooth muscle cells. Diabetes 48: 855-864, 1999.

37. Cameron NE, Eaton SE, Cotter MA and Tesfaye S: Vascular factors and metabolic interactions in the pathogenesis of diabetic neuropathy. Diabetologia 44: 1973-1988, 2001.

38. Klimova T and Chandel NS: Mitochondrial complex III regulates hypoxic activation of HIF. Cell Death Differ 15: 660-666, 2008.

39. Fandrey J, Gorr TA and Gassmann M: Regulating cellular oxygen sensing by hydroxylation. Cardiovasc Res 71: 642-651, 2006.

40. Madkor HR, Mansour SW and Ramadan G: Modulatory effects of garlic, ginger, turmeric and their mixture on hyperglycaemia, dyslipidaemia and oxidative stress in streptozotocin-nicotinamide diabetic rats. Br J Nutr 105: 1210-1217, 2011. 